\title{
SBC2009-206043
}

\section{CALCIUM SIGNALING IN BONE CELL NETWORKS INDUCED BY FLUID FLOW}

\author{
X. Lucas Lu (1), Bo Huo (2), Andrew D. Baik (1), X. Edward Guo (1)
}

\author{
Department of Biomedical Engineering \\ Columbia University \\ New York, NY
}

\author{
Institute of Mechanics \\ Chinese Academy of Sciences \\ Beijing, P.R. China
}

\section{INTRODUCTION}

Mechanical stimuli such as fluid flow can induce robust multiple intracellular calcium $\left(\left[\mathrm{Ca}^{2+}\right]_{\mathrm{i}}\right)$ peaks in connected bone cell networks [1]. This fluid flow induced oscillation of $\left[\mathrm{Ca}^{2+}\right]_{\mathrm{i}}$ can come from two sources: intracellular $\mathrm{Ca}^{2+}$ stores (e.g., endoplasmic reticulum, ER) and the extracellular environment. Moreover, $\left[\mathrm{Ca}^{2+}\right]_{i}$ signaling is mediated by various molecular pathways, such as $\mathrm{IP}_{3}, \mathrm{ATP}, \mathrm{PGE}_{2}$, and NO. Osteocytes are believed to comprise a sensory network in bone tissue that monitors in vivo mechanical loading and triggers appropriate adaptive responses from osteoblasts and osteoclasts [2]. It is also well recognized that osteoblasts, the cells responsible for bone formation, can directly sense and respond to mechanical stimulation (e.g., fluid flow). In the present study, two types of cell networks were constructed in vitro with osteocyte-like and osteoblast-like cells, respectively, by using microcontact printing and self assembled monolayer (SAM) technologies. The calcium responses of the two types of cell networks to fluid flow were recorded, quantitatively analyzed, and compared. Then we examined how the $\left[\mathrm{Ca}^{2+}\right]_{\mathrm{i}}$ response in the osteocyte cell network was influenced by gap junctions, intra/extracellular calcium sources, and other various molecular pathways.

METHODS

Osteocyte-like MLO-Y4 cells or osteoblast-like MC3T3-E1 cells were seeded and cultured on patterned slides prepared with microcontact printing and SAM technologies, forming in vitro bone cell networks connected through functional intercellular gap junctions (Fig. 1). To indicate $\left[\mathrm{Ca}^{2+}\right]_{\mathrm{i}}$, the cells were loaded with Fura-2 AM. During the flow experiment, the slide was mounted in a parallel-plate flow chamber, which was connected to a magnetic gear pump to generate steady fluid flow with a constant 20 dyne $/ \mathrm{cm}^{2}$ shear stress on the cell surface. The $\left[\mathrm{Ca}^{2+}\right]_{\mathrm{i}}$ responses of the bone cell network were recorded by a high speed CCD camera for a period of 10 minutes: one minute for baseline and 9 minutes after the onset of flow. To quantitatively analyze the temporal characteristics of the recorded $\left[\mathrm{Ca}^{2+}\right]_{\mathrm{i}}$ responses, a set of parameters were defined and illustrated in Fig. 2, including the total number of responsive calcium peaks, the time to reach the first calcium peak, the relaxation time, and the time in-between successive calcium peaks. The results from the two different cell types were compared with a Student t-test.

To investigate the calcium signaling mechanism of bone cell networks, MLO-Y4 cell networks were employed and 8 experimental groups were designed. Besides the untreated group (81 cells), seven groups treated with specific pharmacological agents respectively were tested and all experiments were repeated at least three times: (1) Extracellular $\mathrm{Ca}^{2+}$-free medium (66 cells); (2) $\mathrm{ER} \mathrm{Ca}^{2+}$ depletion by thapsigargin (TG) (44 cells); (3) Prostaglandin $\mathrm{E}_{2}\left(\mathrm{PGE}_{2}\right)$ blocking by NS-398 (50 cells); (4) Nitric oxide (NO) blocking by L-NMMA (60 cells); (5) Gap junctions blocking by $18 \alpha-G A$ (50 cells); (6) ATP blocking by suramin (40 cells); (7) Vehicle control, (DMSO) (67 cells). The $\left[\mathrm{Ca}^{2+}\right]_{\mathrm{i}}$ response times were compared between different groups. One-way analysis of variance with Bonferroni's post hoc analysis was performed to determine statistical differences between different treatments/groups. NS398, TG, and $18 \alpha-G A$ were dissolved in DMSO, so results from these three groups were compared with those from the DMSO vehicle control group. L-NMMA, Suramin, and $\mathrm{Ca}^{2+}$ free medium treated groups were compared with the untreated group.

\section{RESULTS}

A set of typical $\left[\mathrm{Ca}^{2+}\right]_{\mathrm{i}}$ response curves from MC3T3-E1 and MLO-Y4 cells are shown in Fig. 3. Both cell types display multiple calcium spikes during the 9-minute shear loading period. The MC3T3E1 cells released a strong $\left[\mathrm{Ca}^{2+}\right]_{\mathrm{i}}$ spike at the onset of flow which was 
later followed by a few weaker spikes. MLO-Y4 cells, however, tended to demonstrate more spikes without a significant decrease in the $\left[\mathrm{Ca}^{2+}\right]_{\mathrm{i}}$ spike magnitude. The mean value of the number of responsive peaks of MLO-Y4 cells is $6.7 \pm 3.8$ (mean $\pm \mathrm{sd}$ ), which is significantly higher than that of MC3T3-E1 cells $(2.9 \pm 1.8, p<0.05)$ (Fig. 4A). Moreover, 97\% MLO-Y4 cells reached the first $\left[\mathrm{Ca}^{2+}\right]_{\mathrm{i}}$ peak in less than 20 seconds $(16 \pm 4 \mathrm{~s})$, significantly shorter $(p<0.001)$ than the MC3T3-E1 cells' time (36 \pm 26 s) (Fig. 4B). This implies that either the extracellular $\mathrm{Ca}^{2+}$ can be pumped into MLO-Y4 cells faster, or the intracellular $\mathrm{Ca}^{2+}$ store in MLO-Y4 cells can release $\mathrm{Ca}^{2+}$ in a shorter time, or both. It also takes MLO-Y4 cells less time to reduce its high $\left[\mathrm{Ca}^{2+}\right]_{\mathrm{i}}$ concentration (Fig. 4C, MLO-Y4: $23 \pm 13 \mathrm{~s}$, MC3T3: $44 \pm 70 \mathrm{~s}$, $p<0.05)$. No significant difference was detected for parameter $t_{3}$, time between first and second peaks, in the two groups (Fig. 4D).

Since the MLO-Y4 cells are more active and sensitive to fluid flow than the MC3T3-E1 cells, the MLO-Y4 cell networks were employed to investigate the calcium signaling mechanisms in bone cell networks. In the untreated group, over $73 \%$ of the cells in the network were able to respond three or more times with an overall mean value of $4.7 \pm 2.7$ peaks (Fig. 5). The vehicle control group had a lower number of responsive peaks than the untreated group (3.0 \pm 1.9 , $p<0.05$ ). The ER $\mathrm{Ca}^{2+}$ store depleted group and extracellular ATP blocked groups generated the least number of responsive peaks, which was slightly greater than one (1.4 \pm 0.7 and $1.2 \pm 0.6$ respectively). This implies that both intracellular ER $\mathrm{Ca}^{2+}$-store and extracellular ATP play critical roles in the multiple $\left[\mathrm{Ca}^{2+}\right]_{\mathrm{i}}$ responses in bone cells. Inhibition of either will disable the cell's ability to release more than one $\left[\mathrm{Ca}^{2+}\right]_{\mathrm{i}}$ spike. Interestingly, the removal of extracellular calcium completely abolished the $\left[\mathrm{Ca}^{2+}\right]_{\mathrm{i}}$ response even when the cells had a functional ER $\mathrm{Ca}^{2+}$ store. The $18 \alpha-\mathrm{GA}$ treated group (gap junctions blocked), on the contrary, showed no decrease in the multiple responses. This result is consistent with those we found by using CX43 (major protein for gap junctions) knockout bone cells.

\section{CONCLUSION}

In conclusion, under the same mechanical stimulation, MLO-Y4 cells can release $\left[\mathrm{Ca}^{2+}\right]_{\mathrm{i}}$ spikes at a much higher frequency than MC3T3-E1 cells can. It also takes a much shorter time for the MLO$\mathrm{Y} 4$ cells to release a $\left[\mathrm{Ca}^{2+}\right]_{\mathrm{i}}$ spike after the onset of flow and to recover the intracellular calcium store. These results may imply that osteocytes, as the major mechanical sensor in bone, are more sensitive and active under mechanical stimulations than osteoblasts.

In the present study, we also investigated the multiple $\left[\mathrm{Ca}^{2+}\right]_{\mathrm{i}}$ peaks in the osteocyte cell network under fluid flow and their dependence on gap junctions, intra/extracellular calcium sources, and various molecular pathways. The results identified the importance of the extracellular calcium source, intracellular calcium store, and the ATP pathway in the calcium oscillations in osteocyte networks under mechanical loading.
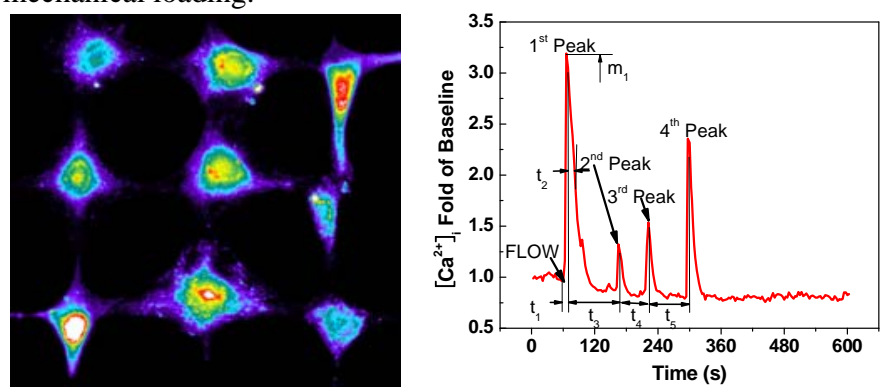

Figure 1 (L): A fluorescence image of a patterned MLO-Y4 cell network in pseudo-color; Figure 2 (R): A typical calcium response of a cell and the definitions of temporal parameters employed in the present study.
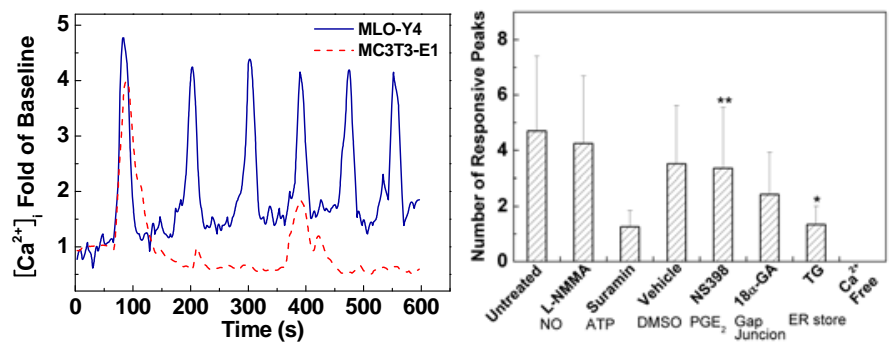

Figure 3 (L): Two typical calcium response curves from MC3T3-E1 and MLO-Y4 cells; Figure 5 (R): The average number of calcium response peaks of cells from the eight pharmacological agents treated groups. Every group was statistically different with each other except those marked. *: not with suramin; **: not with Vehicle. $p<0.05$.
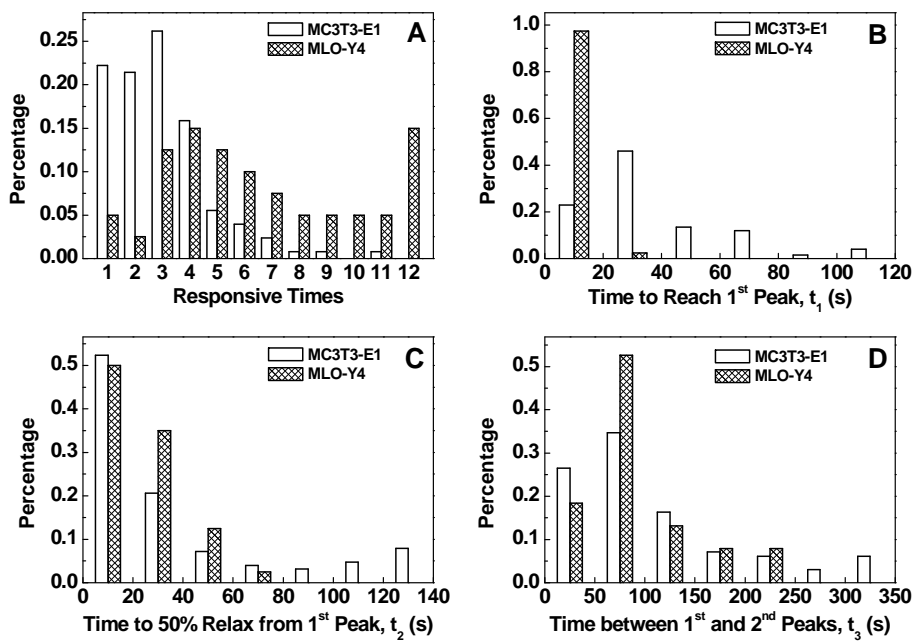

Figure 4: Comparison of temporal parameters in $\left[\mathrm{Ca}^{2+}\right]_{\mathrm{i}}$ responses from MC3T3-E1 and MLO-Y4 cells: (A) total responsive times during steady fluid flow stimulation; (B) time to reach the $1^{\text {st }}\left[\mathrm{Ca}^{2+}\right]_{i}$ peak after the onset of flow; (C) time to $50 \%$ relaxation after the $1^{\text {st }}$ peak; (D) time between $1^{\text {st }}$ and $2^{\text {nd }}$ peaks.

1. Huo, B., et al., 2008, "Fluid Flow Induced Calcium Response in Bone Cell Network," Cellular and Molecular Bioengineering, Vol. 1(1), pp. 58-66.

2. Tatsumi, S., et al., 2007, "Targeted ablation of osteocytes induces osteoporosis with defective mechanotransduction," Cell Metab, Vol. 5(6), pp. 464-75. 